\title{
Quantum dots go on display
}

\section{Adoption by TV makers could expand the market for light-emitting nanocrystals.}

\section{BY KATHERINE BOURZAC}

$\mathrm{L}$ ive from your living room, in supersaturated colour: it's the quantum-dot TV! Researchers working with nanoscale fluorescent particles called quantum dots have long predicted groundbreaking achievements, such as ultra-efficient light-emitting diodes (LEDs) and solar cells, but the technology has found mainly niche applications. That could change with the announcement last week that QD Vision, based in Lexington, Massachusetts, would supply Sony Corporation of Tokyo with quantum dots for flat-screen televisions that will transmit more richly coloured images than other TVs on the market.

Demand for quantum-dot displays, say industry watchers, could benefit quantum-dot companies, bring down the price of these nanomaterials and boost other applications that have stalled. "Displays are a potential market that could help quantum-dot companies find traction," says Jonathan Melnick, an analyst at Lux Research in Boston, Massachusetts.

Quantum dots are crystals about 10 nanometres in diameter, made from a semiconductor material, commonly cadmium selenide. They are so tiny that their shape and size affect the quantum properties of their electrons, in particular their energy gap - the energy needed to kick electrons into a higher-energy band - which determines the colour of light that the material can emit. Whereas a bulk semiconductor is limited to emitting a single colour of light, researchers can tune the precise colour a quantum dot will absorb and re-emit by tailoring its size.

Discovered in 1981, quantum dots did not find applications until 2002. That was when the Quantum Dot Corporation of Hayward, California, began selling them to cell biologists, who prize them as fluorescent imaging labels for proteins and other biological molecules. As recently as 2010, the biomedical sector was responsible for US\$48 million of \$67 million in total quantum-dot revenues, according to BCC Research of Wellesley, Massachusetts.

Quantum dots have shown promise for electronics, too - for example in solar cells, in which a mix of quantum dots tuned to absorb different wavelengths of light could capture more of the energy in the solar spectrum. But one hurdle to their exploitation was their temperature sensitivity. Near the backlight of a liquid-crystal display (LCD), for example, temperatures can be around $100^{\circ} \mathrm{C}$. At this temperature, the dots lose efficiency and up to half

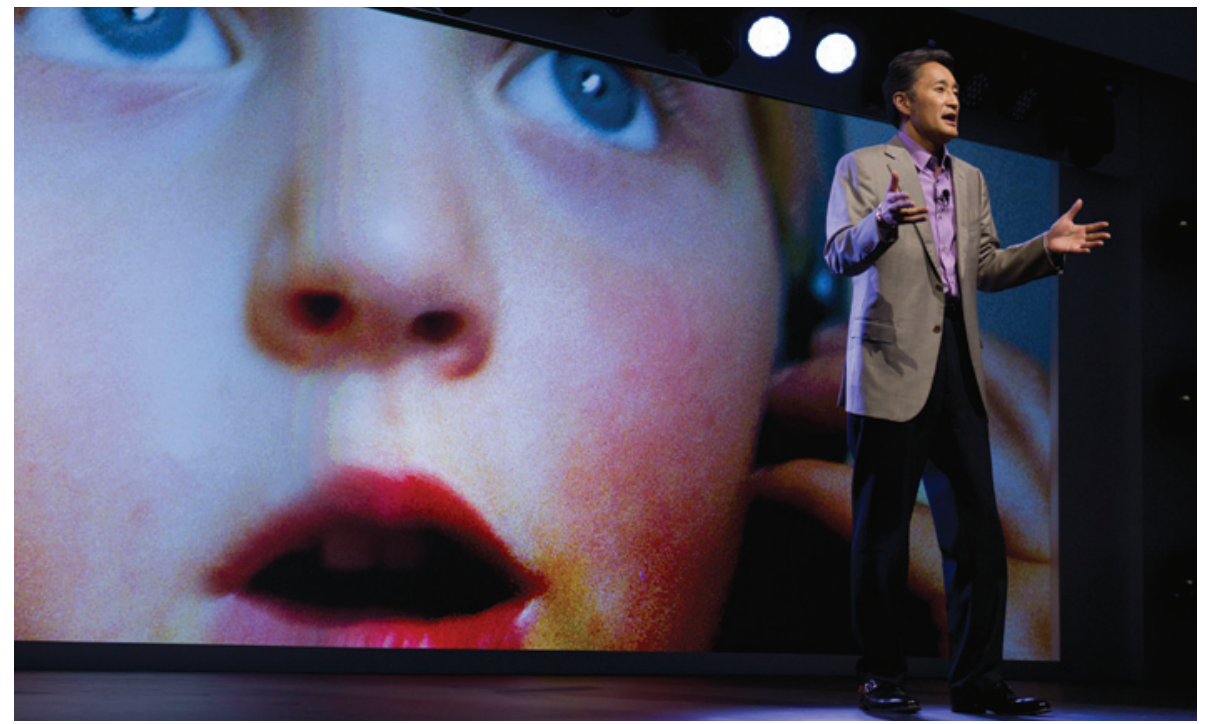

Sony has announced that it will embed quantum dots in its latest flat-screen televisions.

of their brightness, says QD Vision co-founder and chief technology officer Seth Coe-Sullivan. He says that the company spent a long time tuning the chemistry of its quantum dots to make them stable at higher temperatures.

Moungi Bawendi, a chemist at the Massachusetts Institute of Technology in Cambridge and a co-founder of QD Vision, admits that the company also made some business miscalculations. For its first product, in 2009, it provided Nexxus Lighting of Charlotte, North Carolina, with quantum-dot coatings to convert the harsh glare of LEDs into a warmer glow, to make them more appealing as long-life, low-energy light bulbs. But Bawendi says that LED designs and technology for the light-bulb market evolved too fast for the quantum-dot coatings to keep up. "You design something, and six months later it doesn't work," Bawendi says. "Television technology is more stable."

His optimism will be tested this spring with the company's quantum-dot debut in Sony LCD televisions, to be sold under the Triluminos brand name. The contrast with today's flat screens begins with the light source. Conventional LCDs use a high-intensity blue LED backlight whose glow is converted by a phosphor coating to create a broadband, white light used to make the moving TV images. The new Triluminos televisions instead pair an uncoated blue LED with a thin glass tube filled with quantum dots. Two kinds of quantum dots in the tube absorb some of the blue light from the backlight and re-emit it as pure red and green light. The resulting white light is more intense at the wavelengths of these three specific colours than the white light made by a phosphor-coated LED, so that more colour comes through in the images.

Another quantum-dot company, Nanosys of Palo Alto, California, is providing $3 \mathrm{M}$ of St Paul, Minnesota, with material for a similar product. $3 \mathrm{M}$ will make a polymer film seeded with quantum dots that does the same job as QD Vision's glass tube. The film is layered between the LCD's stack of light filters, diffusers and polarizers, and similarly converts raw blue light into white light made up of pure colours. Nanosys and $3 \mathrm{M}$ announced their partnership in June 2012, but have not yet named any customers.

BCC predicts that, by 2015, optoelectronics, including display components, will make up $\$ 310$ million of a total $\$ 666$ million in quantum-dot revenues. Melnick says that these numbers might be overly optimistic, because quantum dots remain expensive. "Even on the low end, they still cost in the hundreds of dollars per gram, and range up to $\$ 10,000$ per gram," he says. But demand from $3 \mathrm{M}$ and Sony could help to bring prices down. Although neither QD Vision nor Nanosys would comment on the volume of material they expect to make this year, or their selling price, both say that they are scaling up their manufacturing volume.

Bawendi is not surprised that it took quantum dots so long to find their footing. "You could argue that 30 years is about the right amount of time from fundamental discovery to applications," he says. 